\title{
Influential factors of loess liquefaction and pore pressure development*
}

\begin{abstract}
The liquefaction of loess under dynamic loading is studied experimentally with a dynamic triaxial test system. The effects of over-consolidation ratio (OCR), saturation degree and the frequency of dynamic loading upon loess liquefaction are investigated. The development of pore pressure within loess samples is also discussed. Based on the experimental results, the empirical relationship between pore pressure ratio and loading cycle number ratio is established for normal consolidated saturated loess.
\end{abstract}

Keywords Loess liquefaction - Over-consolidation ratio $\cdot$ Loading frequency $\cdot$ Saturation degree $\cdot$ Pore pressure

\section{Introduction}

Loess exists extensively in the northwest of China, where the seismic disasters such as land slide and subsidence often occur during earthquake events. The field and laboratory investigations in recent years have shown that the saturated loess with high moisture has high liquefaction potential and flow failure potential. The loess liquefaction caused by an intensive earthquake may make the foundation of building lose stability or induce mudflow in a hilly land. Loess liquefaction has been recognized as one of the most serious seismic disasters [1]. Therefore, to further investigate the mechanism of loess liquefaction is important to civil engineers working on earthquake proof design.

To date, there has been very little research work on loess liquefaction, which was mainly carried out in Japan, the USA

*The project supported by the National Natural Science Foundation of China (50178005)

C. G. Zhao (乘 · Z. M. Yang · Y. N. Zhang

School of Civil Engineering, Beijing Jiaotong University, Beijing 100044, China

E-mail: cgzhao@center.njtu.edu.cn

F. P. Gao

Institute of Mechanics, Chinese Academy of Sciences,

Beijing 100080, China and China [1-4]. The research on loess liquefaction has been reviewed in Ref. [4].

In this paper, loess liquefaction is studied experimentally with a dynamic triaxial apparatus. The effects of overconsolidation ratio, saturation degree of loess and the frequency of dynamic loading on loess liquefaction are investigated, and moreover, the development of pore pressure within loess under dynamic loading is discussed.

\section{Experimental method}

The experiments have been conducted with MTS810 hydraulic-servo dynamic triaxial test system manufactured by MTS Co. in the USA. The loess samples are all $39.1 \mathrm{~mm}$ in diameter, and $80.0 \mathrm{~mm}$ in height. The prototype samples of Malan Loess in the experiments were taken from Qilihe District of Lanzhou city, China. The physical properties of the samples are listed in Table 1. The reconstituted loess samples are prepared by dividing each sample into five layers, each of which is compacted with ten hits. The wet density of reconstituted loess samples is $1.68 \mathrm{~g} / \mathrm{cm}^{3}$ and the dry density is $1.49 \mathrm{~g} / \mathrm{cm}^{3}$. Water head method is used for the saturation of undisturbed samples, and back-pressure method is used for that of remolded samples. Seed's initial liquefaction is taken as the criterion for loess liquefaction.

\section{Influential factors of loess liquefaction}

Whether the liquefaction of loess can be triggered depends mainly on the consolidation state, initial stress level of loess and the properties of dynamic loading. In this section, the effects of over-consolidation ratio (OCR), saturation degree and the frequency of dynamic loading upon loess liquefaction will be analyzed. In accordance with Seed's initial liquefaction criterion, the normalized cyclic stress ratio $\left(\tau_{c} / \sigma_{0}\right)$ and the number of loading cycles $\left(N_{l}\right)$ are used for evaluating soil initial liquefaction, where $\tau_{c}$ is the cyclic shear stress at a point within soil, $\sigma_{0}$ is the initial effective vertical stress at 
Table 1 Basic physical properties of undisturbed loess

\begin{tabular}{|c|c|c|c|c|c|c|c|c|c|}
\hline \multicolumn{5}{|c|}{ Physical indexes of loess in natural state } & \multirow[t]{2}{*}{ Specific gravity } & \multirow[t]{2}{*}{ Plastic index } & \multicolumn{3}{|c|}{ Composition of grains } \\
\hline $\begin{array}{l}\text { Moisture content } \\
(\%)\end{array}$ & $\begin{array}{l}\text { Wet density } \\
\left(\mathrm{g} / \mathrm{cm}^{3}\right)\end{array}$ & $\begin{array}{l}\text { Dry density } \\
\left(\mathrm{g} / \mathrm{cm}^{3}\right)\end{array}$ & Void ratio & $\begin{array}{l}\text { Degree of } \\
\text { Saturation }(\%)\end{array}$ & & & $\begin{array}{l}\text { Clay } \\
(\%)\end{array}$ & $\begin{array}{l}\text { Silt } \\
(\%)\end{array}$ & $\begin{array}{l}\text { Sand } \\
(\%)\end{array}$ \\
\hline 13.03 & 1.42 & 1.26 & 1.16 & 30.44 & 2.71 & 10 & 13 & 72 & 15 \\
\hline
\end{tabular}

the same point. Note that isotropic consolidation is considered in this study, i.e. $\sigma_{0}=\sigma_{3}$, in which $\sigma_{3}$ is the confining pressure.

\subsection{Effect of over-consolidation ratio}

The variation of cyclic stress ratio with number of loading cycles for various over-consolidation ratios is shown in Fig. 1. It can be seen from the figure that the higher the over-consolidation ratio is, the more loading cycles are needed for triggering initial liquefaction for a certain cyclic stress ratio, and that the cyclic strength increases with the increase of OCR. The typical development of pore pressure $\left(u_{t}\right)$ within normally consolidated saturated undisturbed loess with loading cycle $(N)$ and that within over-consolidated one are illustrated in Fig. 2(a) and Fig. 2(b), respectively. It is shown in the two figures that the rate of pore pressure buildup within normally consolidated loess sample is higher than that within over-consolidated one. Furthermore, the dilation of soil skeleton may occur in the over-consolidated loess sample (see Fig. 2(b)). Therefore, the liquefaction resistance of over-consolidated loess is higher than that of normally consolidated one.

\subsection{The effect of the frequency of dynamic loading}

The relationship between cyclic stress ratio $\tau_{c} / \sigma_{0}$ and number of loading cycles $N_{l}$ to induce initial liquefaction with various loading frequencies $(f)$ for undisturbed normally consolidated saturated loess and that for reconstituted loess are shown in Fig. 3(a) and Fig. 3(b), respectively. For the same value of $\tau_{c} / \sigma_{0}$, the higher the loading frequency is, the larger $N_{l}$ is required to induce initial liquefaction of loess with a fixed value of confining pressure (i.e. $\sigma_{3}=100 \mathrm{kPa}$ ). When

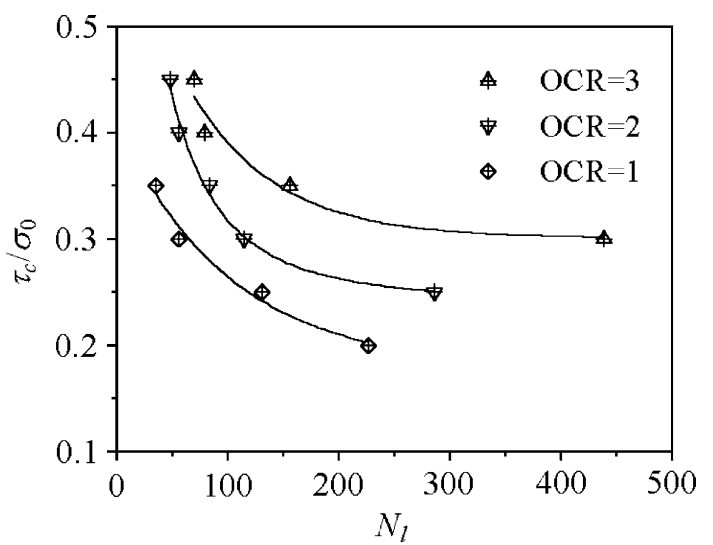

Fig. 1 Variation of cyclic stress ratio with number of loading cycles for various over-consolidation ratios $\left(\sigma_{3}=100 \mathrm{kPa}, f=1 \mathrm{~Hz}\right)$
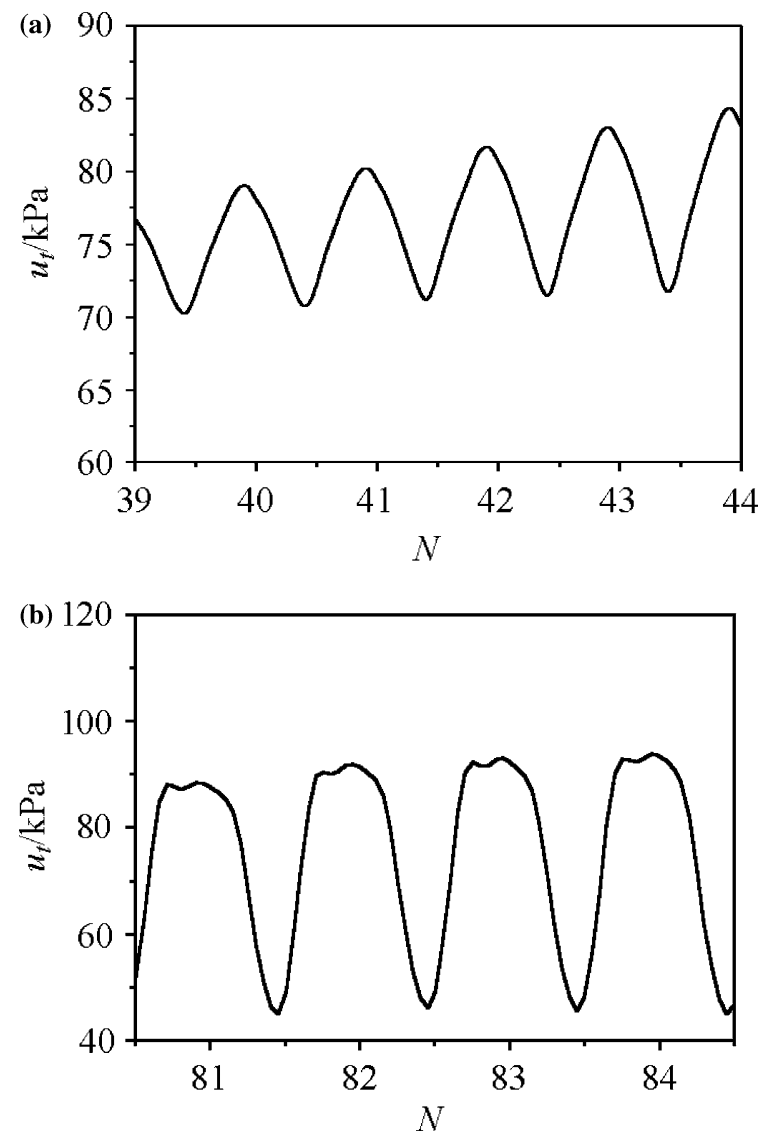

Fig. 2 Typical pore pressure development within saturated undisturbed loess (a) Normally consolidated loess (b) Over-consolidated loess

maintaining the same value of $N_{l}$, the lower the loading frequency is, the smaller $\tau_{c} / \sigma_{0}$ is needed for triggering loess liquefaction.

\subsection{The effect of the degree of saturation}

It is also interesting to investigate the effect of the degree of saturation $\left(S_{r}\right)$ on loess liquefaction. In the experiments, the undisturbed loess samples are normally consolidated under the confining pressure $\sigma_{3}=100 \mathrm{kPa}$. The frequency of cyclic loads $f=1 \mathrm{~Hz}$ and the cyclic stress ratio $\tau_{c} / \sigma_{0}=0.3$. The relationship between the degree of saturation $S_{r}$ and the number of loading cycle $N_{l}$ to induce initial liquefaction is shown in Fig. 4. It is indicated that with the increase of $S_{r}$, a smaller $N_{l}$ is needed for triggering loess liquefaction.

Figure 5 shows the variation of pore pressure ratio $\left(u / \sigma_{0}\right)$ with loading cycle number ratio $\left(N / N_{l}\right)$ for various degrees 

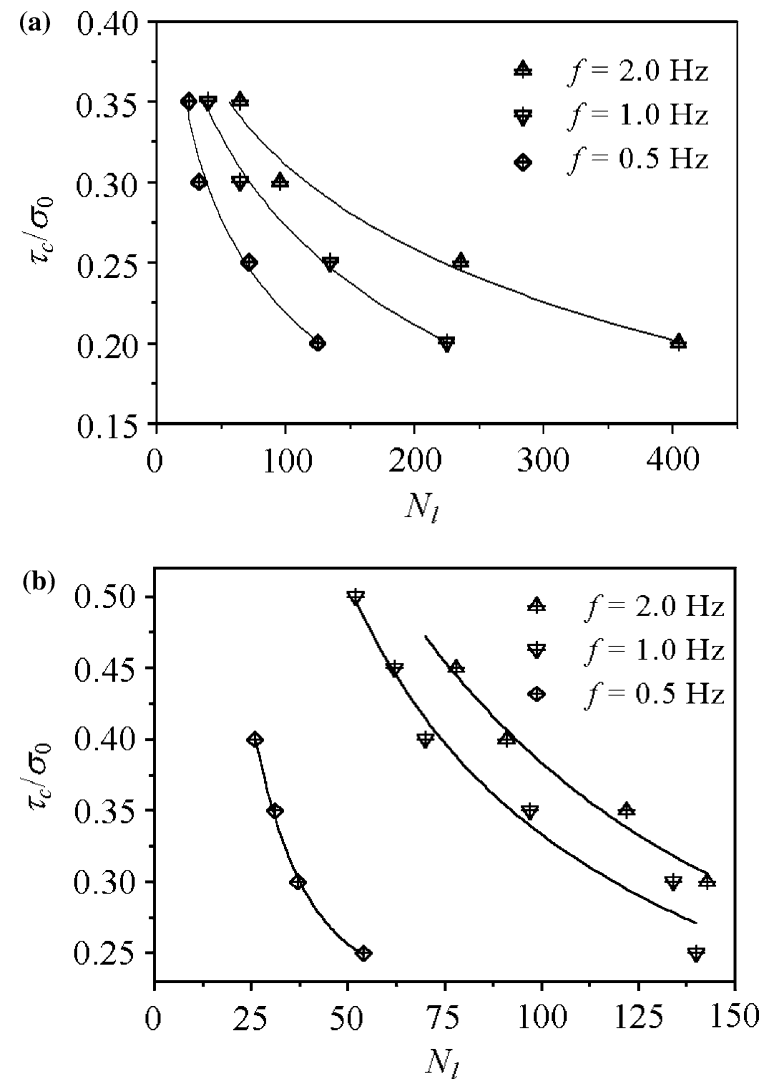

Fig. 3 Variation of cyclic stress ratio with number of loading cycles for various loading frequencies $\left(\sigma_{3}=100 \mathrm{kPa}\right)(\mathbf{a})$ Undisturbed loess (b) Reconstructed loess

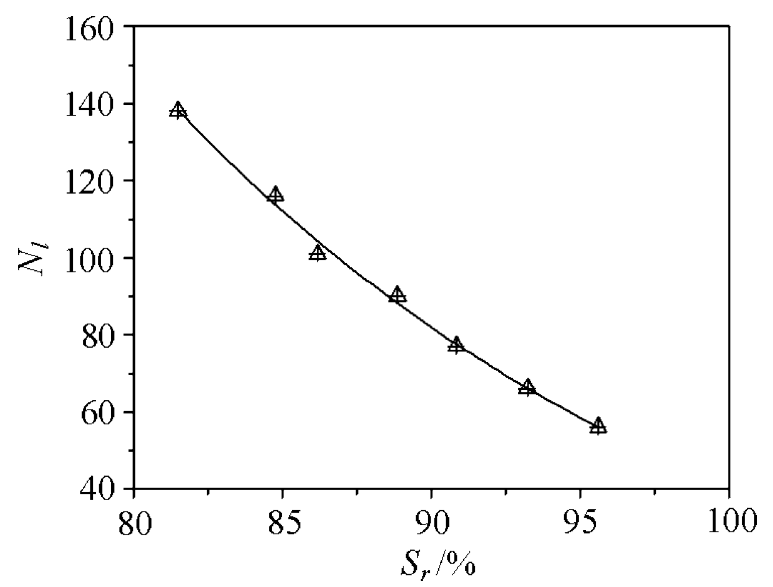

Fig. 4 The relationship between the degree of saturation and the number of loading cycle to induce loess initial liquefaction

of saturation $\left(S_{r}\right)$ of undisturbed loess samples, where $N$ is the number of loading cycles required to develop the pore water pressure with peak value $u$. It is shown in the figure that, at the beginning stage of cyclic loading, the rate of excess pore pressure buildup is much higher in loess samples with higher value of $S_{r}$ than that in the loess samples with lower value of $S_{r}$. This indicates that the resistant strength to liquefaction increases with the decrease of the degree of saturation.

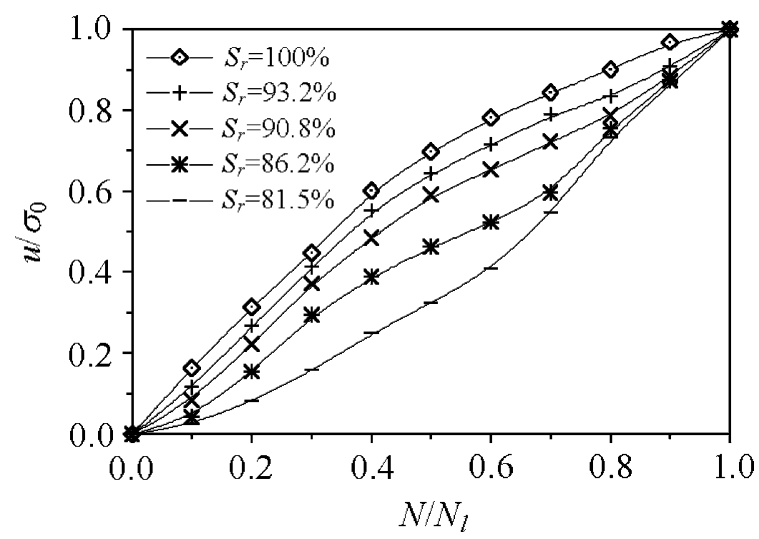

Fig. 5 Variation of pore pressure ratio with loading cycle number ratio for various degrees of saturation of undisturbed loess

\section{Development of pore-water pressure}

It is well known that, the development of pore water pressure under dynamic loading has a great influence on loess deformation and its strength, which is the key for the analysis of loess stability with the effective stress method. So it is essential to establish the rules for the development of pore pressure, including its appearing, developing and disappearing. However, there is still very little research work on it till now. In this section, based on the experimental results, the formula for describing the development of pore pressure is established.

Our experiments have shown that under dynamic loading, the pore pressure of undisturbed normally consolidated saturated loess increases more quickly at first, and then increases slower. The shape of curve is less affected by the confining pressure, the frequency of dynamic loading and cyclic stress ratio. Based on the experimental results, the empirical relationship between pore pressure ratio $u / \sigma_{0}$ and loading cycle number ratio $N / N_{l}$ can be written as

$u / \sigma_{0}=\frac{1}{2}\left\{\frac{1}{2}\left[1-\cos \left(\pi N / N_{l}\right)\right]\right\}^{a}-\frac{1}{2} \mathrm{e}^{-b N / N_{l}}+0.5$

where $a$ and $b$ are the fitting parameters, depending on the physical properties of loess. For the loess whose basic physical parameters are shown in Table 1 , the values of $a$ and $b$ are determined as 0.55 and 2.34, respectively. As shown in Fig. 6, the mean experimental values are fitted quite well with the values calculated with Eq. (1). It is noted that the above formula can be used only for describing the pore pressure development of normal consolidated saturated loess.

The pore pressure development of over-consolidated saturated undisturbed loess samples under dynamic loading may be different from that of normally consolidated ones. Figure 7 shows relationship between pore pressure ratio $u / \sigma_{0}$ and loading cycle number ratio $N / N_{l}$ for various over-consolidation ratios and with the fixed values of confining pressure $\left(\sigma_{3}=100 \mathrm{kPa}\right)$, frequency $(f=1 \mathrm{~Hz})$ and cyclic stress ratio $\left(\tau_{c} / \sigma_{0}=0.3\right)$. As illustrated in Fig. 7 , with the increase of over-consolidation ratio (OCR), the rate of pore pressure within loess under dynamic loading gets lower. 


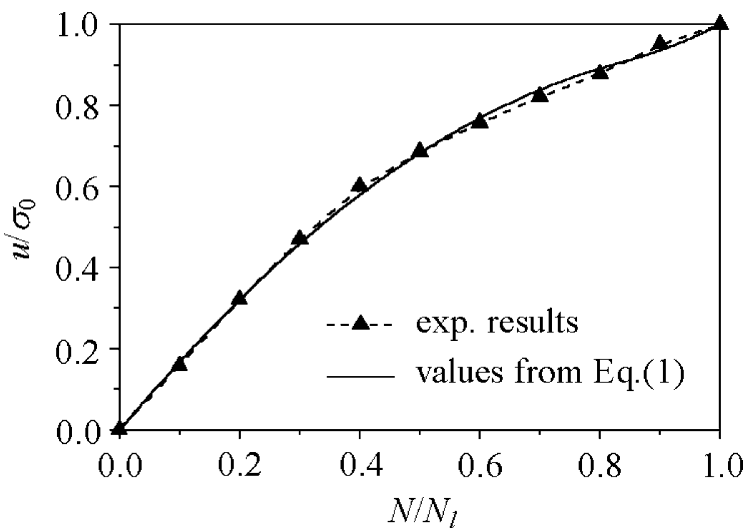

Fig. 6 Comparison of calculated values and experimental results of pore pressure buildup $\left(u / \sigma_{0}\right.$ vs $\left.N / N_{l}\right)$

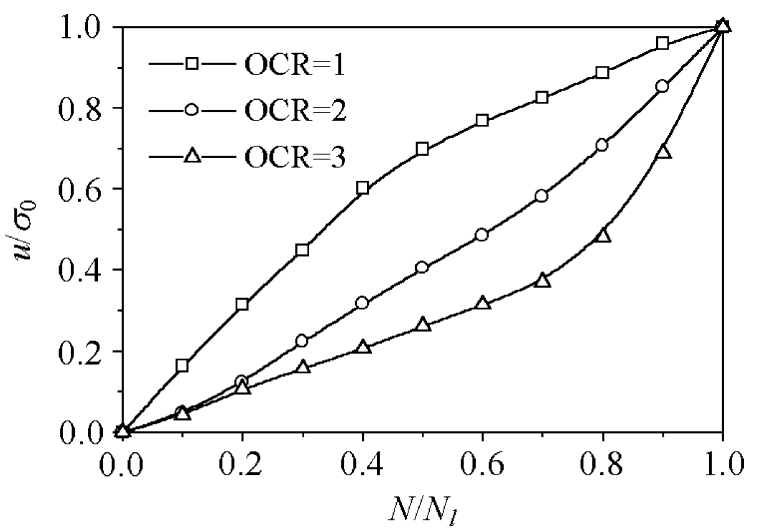

Fig. 7 Variation of pore pressure ratio with loading cycle number ratio for various over-consolidation ratios $\left(\sigma_{3}=100 \mathrm{kPa}, f=1 \mathrm{~Hz}, \tau_{c} / \sigma_{0}=\right.$ $0.30)$

\section{Conclusions}

The present work mainly focuses on the liquefaction of loess under dynamic loading. Based on the triaxial experiment results, the following conclusions can be drawn:
(1) Over-consolidation ratio of loess and the frequency of dynamic loading have a great influence on the liquefaction of saturated loess under dynamic loading. For a fixed value of cyclic stress ratio, with the increase of OCR, more loading cycles are required to trigger the liquefaction of saturated loess. For normally consolidated saturated loess, the higher the loading frequency is, the more loading cycles are needed.

(2) The saturation degree also has an influence on the liquefaction of loess. With the saturation degree increasing, the excess pore pressure within loess increases greatly, and thereby the liquefaction resistance gets lower.

(3) The empirical relationship between pore pressure ratio and loading cycle number ratio is established for norma consolidated saturated loess. Moreover, the pore pressure development within over- consolidated saturated loess is different from that within normally consolidated one. The rate of pore pressure buildup decreases with the increase of OCR.

Acknowledgements The authors would like to thank Professor Wang Lanmin of Seismic Bureau of Shan Xi for all his kind help and great support during the course of taking loess samples.

\section{References}

1. Ishihara, K., Okusa, S., Oyagi, N., Ishchuk, A.: Liquefaction induced flowslide in the collapsive loess deposit on Soviet Tajik. Soils and Foundations, 30, 73-89 (1990)

2. Guo, T.Q., Prakash, S.: Liquefaction of silts and silt-clay mixtures. ASCE, Journal of Geotechnical and Geoenvironmental Engineering 125, 706-710 (1999)

3. Wang, L.M., Liu, H.M., Li, L., Sun, C.S.: Experimental research on mechanism and characters of saturated loess liquefaction. Chinese Journal of Geotechnical Engineering 22, 89-94 (in Chinese) (2000)

4. Yang, Z.M., Zhao, C.G., Wang, L.M., Rao, W.G.: Review of the research on liquefaction of saturated loess. China Civil Engineering Journal 36, 38-43 (in Chinese) (2003) 